\title{
GAMBARAN PENGETAHUAN IBU TENTANG STUNTING PADA BAYI DI BAWAH DUA TAHUN (BADUTA) DI PUSKESMAS MANGANITU KABUPATEN KEPULAUAN SANGIHE
}

\section{DESCRIPTION OF MOTHER'S KNOWLEDGE ABOUT STUNTING IN INFANTS UNDER TWO YEARS AT MANGANITU HEALTH CENTER SANGIHE ISLANDS DISTRICT}

\author{
Jelita Siska Herlina Hinonaung, Astri Juwita Mahihody, Grace Angel Wuaten \\ Program Studi Keperawatan, Jurusan Kesehatan \\ Email: siskahinonaung@gmail.com
}

\begin{abstract}
Abstrak: Stunting merupakan masalah gizi kronis yang menimbulkan dampak serius perkembangan fisik, mental, dan emosional anak-anak, dan bukti menunjukkan bahwa efek dari stunting pada usia muda, khususnya pada perkembangan otak, sulit untuk memperbaikinya pada usia lanjut walaupun jika anak menerima gizi yang tepat. Penelitian ini bertujuan untuk mengambarkan pengetahuan ibu tentang stunting pada Baduta di Wilayah Kerja Puskesmas Manganitu Kabupaten Kepulauan Sangihe. Jenis penelitian ini menggunakan rancangan cross sectional. Penelitian ini dilaksanakan di wilayah kerja Puskesmas Manganitu pada bulan Juni-September 2021. Populasi dari penelitian ini adalah seluruh ibu Baduda di wilayah kerja Puskesmas Manganitu. Teknik pengambilan sampel yaitu consecutive sampling yang dilakukan di beberapa posyandu dari bulan Juni-September 2021. Seluruh ibu balita dibawah usia dua tahun (Baduda) yang datang ke Posyandu serta memenuhi kriteria inklusi dan eksklusi dimasukan menjadi sampel penelitian. Adapun kriteria inklusi adalah ibu Baduda bersedia menjadi responden. Kriteria eksklusinya yaitu ibu Baduda yang memiliki anak yang lahir dengan cacat bawaan. Teknik pengumpulan data menggunakan kuesioner pengetahuan tentang stunting. Analisis data menggunakan komputerisasi. Hasil penelitian menunjukkan mayoritas umur ibu berada pada umur ideal melahirkan $(67,2 \%)$, pendidikan ibu berada pada kategori rendah $(55,2 \%)$, tingkat pengetahuan ibu kurang baik $(58,6 \%)$. Baduda yang mengalami stunting sebanyak $8,6 \%$. Item pertanyaan pengetahuan tentang kekurangan gizi kronis penyebab terjadi stunting menjawab dengan salah sebanyak 58,6\% dan Baduta stunting menjadikan anak rentan terhadap penyakit menjawab dengan salah sebanyak $53,4 \%$. Kesimpulan gambaran pengetahuan ibu tentang stunting pada Baduta di Wilayah Kerja Puskesmas Manganitu Kabupaten Kepulauan Sangihe berada pada kategori rendah.
\end{abstract}

Kata kunci: Pengetahuan, Stunting, Baduda, Sangihe

\begin{abstract}
Stunting is a chronic nutritional problem that seriously affects children's physical, mental and emotional development, and evidence shows that the effects of stunting at a young age, particularly on brain development, are difficult to correct in old age even if children receive proper nutrition. This study aims to describe maternal knowledge about stunting in children under two years old in the Manganitu Community Health Center Work Area, Sangihe Islands Regency. This type of research uses a cross-sectional design. This research was carried out in the working area of the Manganitu Health Center in June-September 2021. The population of this study was all mothers of children under two years old in the work area of the Manganitu Health Center. The sampling technique was consecutive sampling conducted at several Integrated Health Post from JuneSeptember 2021. All mothers of children under two years old who came to the Integrated Health Post and met the inclusion and exclusion criteria were included in the study sample. The inclusion criteria were that children under two years old his mother was willing to be a respondent. The exclusion criteria were children under two years old mothers who had children who were born with congenital defects. The data collection technique used a knowledge questionnaire about stunting. Data analysis using computerization. The results showed that the majority of the mothers were at the ideal age for giving birth (67.2\%), the mother's education was in a low category $(55.2 \%)$, the mother's level of knowledge was not good (58.6\%). Children under two years old who experienced stunting were $8.6 \%$. Question items about knowledge about chronic malnutrition causing stunting were answered incorrectly by $58.6 \%$ and children under two years old stunting making children vulnerable to disease answered incorrectly as much as 53.4\%. The conclusion of the description of maternal knowledge about stunting in children under two years old in the Manganitu Health Center Work Area, Sangihe Islands Regency is in a low category.
\end{abstract}

Keywords: Knowledge, Stunting, children under two years old, Sangihe Islands 


\section{PENDAHULUAN}

Kekurangan gizi terus menimbulkan dampak yang besar. Pada 2018, secara global hampir 200 juta anak balita menderita stunting (Keeley et al., 2019). Di Indonesia pencapaian bidang gizi terkait dengan tumbuh kembang anak masih tertinggal. Jutaan anak Indonesia masih menderita stunting akibat kurang gizi (UNICEF, 2019). Menurut laporan Unicef (2019) pada tahun 2018, hampir 3 dari 10 anak berusia di bawah lima tahun menderita Stunting atau terlalu pendek untuk usia mereka, sedangkan 1 dari 10 kekurangan berat badan atau terlalu kurus untuk usia mereka.

Angka kejadian stunting pada balita di Indonesia masih tergolong tinggi sebesar $30,8 \%$, yang terdiri dari $11,5 \%$ sangat pendek dan $19,3 \%$ pendek (Kemenkes RI, 2018). Menurut laporan Kementerian Kesehatan RI (2018), Di Sulawesi Utara angka kejadian stunting sebesar $25,5 \%$ masih berada dibawah angka nasional. Akan tetapi, angka ini belum memenuhi rekomendasi angka kejadian stunting dari WHO sebesar 20\% (Saptoyo, 2021). Berdasarkan sumber Kementerian Kesehatan RI Tahun 2019 Balita yang mengalami Stunting di Kabupaten Kepulauan Sangihe tahun 2018 sebesar 22,99\% terjadi peningkatan yang sebelumnya di tahun 2016 sebesar 17,30\% dan di tahun 2017 sebesar 22,20\% (Kanwil Ditjen Perbendaharaan Provinsi Sulawesi Utara, 2019).

Stunting (pendek/sangat pendek) adalah kondisi kurang gizi kronis yang diukur berdasarkan indeks tinggi badan menurut umur (TB/U) dibandingkan dengan menggunakan standar WHO tahun 2005. Data tinggi badan pada Riset Kesehatan Dasar (Riskesdas) menjadi analisis untuk status gizi dan tinggi badan setiap anak baduta dikonversikan ke dalam nilai terstandar (Z-score) menggunakan baku antropometri anak balita (Peraturan Menteri Kesehatan Republik Indonesia Nomor 2 Tahun 2020 Tentang Standar Antropometri Anak, 2020). Klasifikasi berdasarkan indikator TB/U kategori stunting adalah sebagai berikut: 1. Sangat pendek: Zscore <-3,0 2. Pendek : Zscore $\geq-$ 3,0 s/d Zscore <-2,0 (Badan Pusat Statistik, 2019).
Stunting pada anak-anak mencerminkan efek yang luas dari kekurangan gizi yang kronis dan menderita penyakit berulang yang disebabkan oleh latar belakang sosial dan ekonomi yang buruk. Stunting pada anak-anak dapat memiliki dampak serius pada perkembangan fisik, mental, dan emosional anak-anak, dan bukti menunjukkan bahwa efek dari stunting pada usia muda, khususnya pada perkembangan otak, sulit untuk memperbaikinya pada usia lanjut walaupun jika anak menerima gizi yang tepat. Selain itu, anak yang mengalami stunting berisiko lebih besar menderita penyakit menular dan tidak menular pada usia dewasa seperti jantung, diabetes, dan penyakit pembuluh darah (Badan Pusat Statistik, 2019).

Pengetahuan merupakan hasil yang dihasilkan setelah individu melakukan penginderaan terhadap suatu objek tertentu (Nurmala et al., 2018). Penelitian Tsaralatifah menunjukkan pengetahuan ibu berhubungan dengan kejadian stunting pada Baduta di Kelurahan Ampel Kota Surabaya (Tsaralatifah, 2020). Sedangkan penelitian Titaley et al., menunujukkan kemungkinan stunting meningkat secara signifikan 1,89 kali pada anak usia 12-23 bulan (Titaley et al., 2019)

Penelitian ini bertujuan untuk mengambarkan pengetahuan ibu tentang stunting pada Baduta di Wilayah Kerja Puskesmas Manganitu Kabupaten Kepulauan Sangihe. Penelitian ini menjadi penting disebabkan penelitian ini belum pernah dilakukan di wilayah Kerja Puskesmas Manganitu dan stunting menjadi salah satu masalah nasional.

\section{METODE PENELITIAN}

Jenis penelitian ini merupakan penelitian non eksperimental dengan pendekatan kuantitatif. Desain penelitian menggunakan rancangan cross sectional. Rancangan cross sectional (studi potong lintang) digunakan untuk mengembangkan hubungan antara variabel dan menjelaskan hubungan yang ditemukan. Penelitian ini dilaksanakan di wilayah kerja Puskesmas Manganitu pada bulan Juni-September 2021. Populasi dari penelitian ini adalah seluruh ibu Baduda di 
wilayah kerja Puskesmas Manganitu. Teknik pengambilan sampel yaitu consecutive sampling yang dilakukan di beberapa posyandu dari bulan JuniSeptember 2021. Seluruh balita dibawah usia dua tahun (Baduda) yang datang ke Posyandu serta memenuhi kriteria inklusi dan eksklusi dimasukan menjadi sampel penelitian. Adapun kriteria inklusi adalah ibu Baduda bersedia menjadi responden. Kriteria eksklusinya yaitu ibu Baduda yang memiliki anak yang lahir dengan cacat bawaan. Teknik pengumpulan data menggunakan kuesioner pengetahuan tentang stunting. Analisis data menggunakan komputerisasi.

\section{HASIL DAN PEMBAHASAN}

Responden penelitian ini sebanyak 58 orang yang tinggal di wilayah kerja Puskesmas Manganitu. Adapun analisis univariabel pada penelitian ini meliputi karakteristik umur ibu, pendidikan ibu, pengetahuan, dan kriteria stunting secara terperinci ditampilkan pada tabel 1 .

Tabel 1 menunjukkan mayoritas umur ibu berada pada umur ideal melahirkan $(67,2 \%)$, pendidikan ibu berada pada kategori rendah $(55,2 \%)$, tingkat pengetahuan ibu kurang baik $(58,6 \%)$. Baduda yang mengalami stunting sebanyak $8,6 \%$.

Tabel 1 Distribusi frekuensi karakteristik responden $(\mathrm{n}=58)$

\begin{tabular}{lrr}
\hline Karakteristik & $\begin{array}{c}\text { Frekuensi } \\
\text { (f) }\end{array}$ & $\begin{array}{c}\text { Persentase } \\
(\%)\end{array}$ \\
\hline Umur ibu & & \\
Tidak Ideal & 19 & 32,8 \\
Ideal & 39 & 67,2 \\
& & \\
Pendidikan Ibu & 32 & 55,2 \\
Rendah & 26 & 44,8 \\
Tinggi & & \\
& & \\
Pengetahuan ibu & 34 & 58,6 \\
Kurang baik & 24 & 41,4 \\
Baik & & \\
Stunting & & \\
Ya & 5 & 8,6 \\
Tidak & 53 & 91,4 \\
\hline
\end{tabular}

Pengetahuan merupakan hasil yang dihasilkan setelah individu melakukan penginderaan terhadap suatu objek tertentu (Nurmala et al., 2018). Hasil penelitian ini menunjukkan pengetahuan ibu tentang stunting berada pada kategori kurang baik. Senada dengan penelitian Wulandini et al., menunjukkan pengetahuan ibu tentang stunting di Puskesmas Rejosari Kota Pekanbaru mayoritas berpengetahuan kurang (Wulandini et al., 2020).

Menurut peneliti, kurangnya pengetahuan ibu tentang stunting dapat disebabkan dalam penelitian sebagian besar responden memiliki tingkat pendidikan yang rendah dan beberapa responden berada pada umur yang belum ideal atau cukup untuk melahirkan dan mengasuh anaknya. Pengetahuan dapat dipengaruhi oleh pendidikan seseorang. Semakin tinggi pendidikan seseorang akan semakin tinggi pengetahuannya dan semakin mudah dalam menerima informasi yang diberikan (Wulandini et al., 2020).

Pendidikan ibu secara praktis berhubungan dengan tumbuh kembang anak (Probosiwi et al., 2017). Penelitian Tsaralatifah menunjukkan semua Baduda dengan stunting dalam penelitiannya memiliki ibu dengan tingkat pendidikan yang rendah (Tsaralatifah, 2020). Ibu dengan tingkat pendidikan rendah berisiko 5,1 kali lebih besar memiliki anak stunting (Rahayu \& Khairiyati, 2014).

Begitupun dengan umur atau usia dapat memengaruhi pengetahuan seseorang. Semakin bertambah umur atau usia akan semakin berkembang daya tangkap dan pola pikirnya sehingga pengetahuan yang diperoleh semakin membaik (Tinungki et al., 2017).

Tabel 2 Gambaran pengetahuan ibu menjawab item pertanyaan $(n=58)$

\begin{tabular}{|c|c|c|}
\hline Item Pertanyaan & $\begin{array}{c}\text { Freku- } \\
\text { ensi } \\
\text { (f) }\end{array}$ & $\begin{array}{c}\text { Persen- } \\
\text { tase } \\
(\%)\end{array}$ \\
\hline \multicolumn{3}{|l|}{ Pengertian Stunting } \\
\hline Salah & 17 & 29,3 \\
\hline Benar & 41 & 70,7 \\
\hline \multicolumn{3}{|l|}{$\begin{array}{l}\text { Kekurangan gizi kronis } \\
\text { penyebab terjadi stunting }\end{array}$} \\
\hline Salah & 34 & 58,6 \\
\hline Benar & 24 & 41,4 \\
\hline \multicolumn{3}{|l|}{$\begin{array}{l}\text { Usia stunting setelah bayi } \\
\text { berusia } 2 \text { tahun }\end{array}$} \\
\hline Salah & 27 & 46,6 \\
\hline Benar & 31 & 53,4 \\
\hline
\end{tabular}




\begin{tabular}{|c|c|c|}
\hline $\begin{array}{l}\text { tingkat kecerdasan tidak } \\
\text { maksimal. } \\
\text { Salah } \\
\text { Benar }\end{array}$ & $\begin{array}{l}27 \\
31\end{array}$ & $\begin{array}{l}46,6 \\
53,4\end{array}$ \\
\hline $\begin{array}{l}\text { Baduta stunting } \\
\text { anak renjadikan } \\
\text { penyakit }\end{array}$ & & \\
\hline Salah & 31 & 53,4 \\
\hline Benar & 27 & 46,6 \\
\hline $\begin{array}{l}\text { Baduda stunting dimasa } \\
\text { akan datang mengalami } \\
\text { kesulitan dalam mencapai } \\
\text { perkembangan fisik. }\end{array}$ & & \\
\hline Salah & 27 & 46,6 \\
\hline Benar & 31 & 53,4 \\
\hline $\begin{array}{l}\text { Umur } \\
\text { esklusif }\end{array}$ pemberian $\quad$ ASI & & \\
\hline Salah & 13 & 22,4 \\
\hline Benar & 45 & 77,6 \\
\hline $\begin{array}{l}\text { Manfaat ASI Eksklusif } \\
\text { mencegah anak } \\
\text { penyakit stunting }\end{array}$ & & \\
\hline Salah & 14 & 24,1 \\
\hline Benar & 44 & 75,9 \\
\hline $\begin{array}{l}\text { Umur pertama } \\
\text { pemberian } \\
\text { MP-ASI }\end{array}$ & & \\
\hline Salah & 25 & 43,1 \\
\hline Benar & 33 & 56,9 \\
\hline $\begin{array}{l}\text { ASI perlu diberikan Pada } \\
\text { anak usia } 1 \text { tahun }\end{array}$ & & \\
\hline Salah & 12 & 20,7 \\
\hline Benar & 46 & 79,3 \\
\hline
\end{tabular}

\begin{tabular}{|c|c|c|}
\hline $\begin{array}{l}\text { Anak usia } 7-23 \text { bulan perlu } \\
\text { meminum obat cacing } \\
\text { Salah } \\
\text { Benar }\end{array}$ & $\begin{array}{l}20 \\
38\end{array}$ & $\begin{array}{l}34,5 \\
65,5\end{array}$ \\
\hline $\begin{array}{lr}\text { Menjaga } & \text { kebersihan } \\
\text { lingkungan rumah dapat } \\
\text { mencegah } & \text { terjadinya } \\
\text { penyakit stunting } & \end{array}$ & & \\
\hline $\begin{array}{l}\text { Salah } \\
\text { Benar }\end{array}$ & $\begin{array}{l}16 \\
42\end{array}$ & $\begin{array}{l}27,6 \\
72,4\end{array}$ \\
\hline $\begin{array}{l}\text { Upaya pencegahan stunting } \\
\text { dengan memantau } \\
\text { pertumbuhan balita } \\
\text { Salah } \\
\text { Benar }\end{array}$ & $\begin{array}{c}6 \\
52\end{array}$ & $\begin{array}{l}10,3 \\
89,7\end{array}$ \\
\hline
\end{tabular}

Baduda di timbang dan di ukur setiap bulan di posyandu

\begin{tabular}{|c|c|c|}
\hline Salah & 3 & 5,2 \\
\hline Benar & 55 & 94,8 \\
\hline $\begin{array}{l}\text { Anak yang stunting } \\
\text { kemungkinan mengalami } \\
\text { obesitas ketika dewasa }\end{array}$ & & \\
\hline Salah & 27 & 46,6 \\
\hline Benar & 31 & 53,4 \\
\hline
\end{tabular}

Kurang pengetahuan ibu tentang nutrisi dapat memicu anak mengalami stunting Salah 16

\section{Benar}

42

72,4

Tabel 2 menunjukkan mayoritas responden menjawab dengan benar item pertanyaan tentang pengertian stunting $(70,7 \%)$, usia stunting $(53,4 \%)$, tingkat kecerdasan stunting $(53,4 \%)$, perkembangan fisik baduda stunting di masa akan datang $(53,4 \%)$, umur pemberian ASI esklusif $(77,6 \%)$, manfaat ASI eksklusif $(75,9 \%)$, umur pemberian MPASI $(56,9 \%)$, usia pemberian minum obat cacing $(65,5 \%)$, menjaga kebersihan rumah $(72,4 \%)$, pemantauan pertumbuhan balita $(89,7 \%)$, penimbangan dan pengukuran setiap bulan di posyandu $(94,8 \%)$, anak yang stunting kemungkinan mengalami obesitas ketika dewasa $(53,4 \%)$, dan kurang pengetahuan ibu tentang nutrisi $(72,4 \%)$.

Pengetahuan ibu menjawab dengan benar umur dan manfaat pemberi ASI eksklusif pada penelitian ini sudah baik. ASI eksklusif adalah pemberian air susu ibu (ASI) tanpa tambahan makanan atau minuman apapun mulai dari bayi berusia 0-6 bulan.

Pengetahuan ibu menjawab dengan benar tentang umur pemberian MPASI pada penelitian ini sudah baik. Senada dengan hasil penelitian Yuliati \& Dewi (2019) yang menunjukkan sebanyak $84,1 \%$ ibu sudah tahu tentang usia mulai diberikan MPASI. Pengetahuan adalah pemahaman teoritis/ praktis dapat diperoleh melalui pendidikan ataupun pengalaman (Yuliati \& Dewi, 2019).

Tabel 2 menunjukkan mayoritas responden menjawab dengan salah item pertanyaan tentang kekurangan gizi kronis penyebab terjadi stunting $(58,6 \%)$ dan Baduta stunting menjadikan anak rentan terhadap penyakit $(53,4 \%)$. Stunting merupakan masalah gizi kronis pada yang ditandai dengan tinggi badan yang lebih pendek dibandingkan dengan anak seusianya. Stunting menyebabkan anak akan lebih rentan terhadap penyakit dan ketika dewasa akan berisiko untuk menderita penyakit degeneratif (Wulandini et al., 2020).

Penelitian Titaley menemukan bahwa anak-anak berusia 12-23 bulan memiliki kemungkinan yang lebih 
besar untuk mengalami stunting dibandingkan mereka yang berusia $<12$ bulan. Masalah tumbuh kembang anak akan terjadi jika pemberian ASI lanjutan tidak disertai dengan pemberian makanan pendamping ASI yang memadai pada umur yang sesuai. Selain itu, peningkatan paparan berbagai penyakit dan kondisi anak sebagai akibat dari bertambahnya usia, seperti paparan kebersihan makanan yang buruk dan sanitasi lingkungan, dapat berkontribusi pada pertumbuhan yang buruk (Titaley et al., 2019).

\section{KESIMPULAN}

Gambaran pengetahuan ibu tentang stunting pada Baduta di Wilayah Kerja Puskesmas Manganitu Kabupaten Kepulauan Sangihe berada pada kategori rendah.

\section{DAFTAR RUJUKAN}

Badan Pusat Statistik. (2019). Kompilasi Data Indikator Pembangunan Berkelanjutan. https://sirusa.bps.go.id/sirusa/index.php/dasar/vie $\mathrm{w} ? \mathrm{kd}=131 \& \mathrm{th}=2019$

Kanwil Ditjen Perbendaharaan Provinsi Sulawesi Utara. (2019). Kajian Fiskal Regional Sulawesi Utara Tahun 2019.

Keeley, B., Chief, E., Little, C., Vrolijk, K., Analyst, D., Wauchope, S., Specialist, P., Al, A., Alnaqshbandi, I., Editor, A., Perellon, C., Editor, S., Reboul-, A., Young, U., Declerck, F., Demaio, A., Harris, J., Hollis, J., Mccoll, K., ... Rudert, C. (2019). Children, food, and nutrition. UNICEF.

Kemenkes RI. (2018). Hasil Riset Kesehatan Dasar Tahun 2018. Kementrian Kesehatan RI, 53(9), 1689-1699.

Peraturan Menteri Kesehatan Republik Indonesia Nomor 2 Tahun 2020 Tentang Standar Antropometri Anak, 1 (2020).
Nurmala, I., Rahman, F., Nugroho, A., Erlyani, N., Laily, N., \& Anhar., V. Y. (2018). Promosi Kesehatan. Airlangga University Press.

Probosiwi, H., Huriyati, E., \& Ismail, D. (2017). Stunting dan perkembangan anak usia 12-60 bulan di Kalasan. Berita Kedokteran Masyarakat, 33(11), 559. https://doi.org/10.22146/bkm.26550

Rahayu, A., \& Khairiyati, L. (2014). RisikoPendidikan Ibu Terhadap Kejadian Stunting Pada Anak 6-23 Bulan (Maternal Education As Risk Factor Stunting of Child 6-23 Months-Old). Journal of Nutrition and Food Research, 37(Ci), 129-136.

Saptoyo, R. D. A. (2021). Apa Itu Stunting? Ketahui Penyebab dan Pencegahannya. Kompas.Com. https://www.kompas.com/tren/read/2021/01/14/1 63500865/apa-itu-stunting-ketahui-penyebabdan-pencegahannya

Tinungki, Y. L., Hinonaung, J. S., Tuwohingide, Y. E., \& Sawelo, J. B. (2017). Asi Eksklusif Oleh Ibu Yang Bekerja Sebagai Perawat. Sesebanua, 3743.

Titaley, C. R., Ariawan, I., Hapsari, D., Muasyaroh, A., \& Dibley, M. J. (2019). Determinants of the stunting of children under two years old in Indonesia: A multilevel analysis of the 2013 Indonesia basic health survey. Nutrients, 11(5). https://doi.org/10.3390/nu11051106

Tsaralatifah, R. (2020). Faktor yang Berhubungan dengan Kejadian Stunting pada Baduta di Kelurahan Ampel Kota Surabaya. Amerta Nutrition, 4(2), 171. https://doi.org/10.20473/amnt.v4i2.2020.171-177

UNICEF. (2019). Status Anak Dunia 2019 Anak, pangan, dan gizi. Www.Unicef.Org/Indonesia. https://www.unicef.org/indonesia/id/status-anakdunia-2019 
65 Jurnal Ilmiah Sesebanua, Volume 5, Nomor 2, November 2021, hlm. 60-65

Wulandini, P., Efni, M., \& Marlita, L. (2020).

Gambaran Pengetahuan Ibu yang Memiliki Balita

Tentang Stunting Di Puskesmas Rejosari

Pekanbaru. Collaborative Medical Journal, 3(1),

8-14.
Yuliati, E., \& Dewi, D. C. (2019). Gambaran Pengetahuan Ibu Dengan Balita Stunting Tentang Pemberian Makan Bagi Balita DI Kecamatan Piyungan, Kabupaten Bantul, Yogyakarta. Seminar Nasional UNRIYO, 1-6.

http://prosiding.respati.ac.id/index.php/PSN/artic le/view/19/0 
Hinonaung, Mahihody, dan Wuaten, Gambaran Pengetahuan Ibu Tentang Stunting...66 